\title{
A Review of Research on Employability of Higher Vocational Students
}

\author{
Yu Jing ${ }^{1, a}$, Arasinah Kamis ${ }^{2, b}$, Ridzwan Bin Che'Rus ${ }^{3, c}$ \\ ${ }^{1}$ Ningxia Polytechnic, Yinchuan, Ningxia, China \\ 2 Sultan Idris Education University, Tanjung Malim, Perak, Malaysia \\ ${ }^{3}$ Sultan Idris Education University, Tanjung Malim, Perak, Malaysia \\ a373898645@qq.com, barasinah@ftv.upsi.edu.my, cridzwan@ftv.upsi.edu.my
}

Keywords: Employability, Employability structure, Higher vocational.

\begin{abstract}
This paper summarizes the concept of employability at domestic and foreign, and outline the definition of employability structure at domestic and foreign, summarize the concept of employability and employability structure of vocational students.
\end{abstract}

\section{Introduction}

In recent years, China's market economic system has been continuously improved, and higher vocational education has developed rapidly. Vocational education aims to cultivate practical and skilled practical talents. This is actually the requirement for vocational education to enhance the training of employability to meet the needs of the job market. There is gap between graduate attributes not only their employment readiness but also their employability skills ${ }^{[1]}$. This paper summarizes the concept of employability and the definition of employability structure at domestic and foreign, and expounds the concept of employment ability and employability structure of higher vocational students.

\section{Concept of employability}

\subsection{The concept of foreign employability}

From the 1950s to the 1970s, it was the origin and initial stage of the research on employability. Employability was more regarded as a labor market tool. Employability, as a socio-economic goal to achieve full employment, was mainly from the perspective of the government. Its research mainly focused on the employment attitude and self-image of the lower-level people and used government intervention to encourage the unemployed to enter the labor market and improve their ability to obtain and maintain long-term employment. Beveridge first introduced this concept in 1909.

The scholar Mayer argues that employability is a common and universal competence that is generally representative of no particular industry or occupation. The ability to be employed, whether at work or in the organization, is an ability that effectively applies skills and knowledge to practical work ${ }^{[2]}$.Mohd Yusof Husain also pointed out that employability is the general skills, quality, knowledge, ability, and characteristics that an individual must possess to succeed in learning and working. They can be applied to different subject areas, different work and living environments $^{[3]}$.

From the perspective of employment services, the Canadian Conference Committee has defined the employability scientifically. The organization believes that employability is the individual's quality and knowledge in order to better meet the needs of the job market in the actual employment environment. Employability can help individuals succeed in obtaining employment and development opportunities and increase their chance of success in employment ${ }^{[4]}$. 


\subsection{The concept of domestic employability}

The study of China's employability started late. It was not until the 1990s that the study of employability was introduced into China. After that, the research was increasingly concerned by researchers.

Domestic scholar Zheng Xiaoming first made clear the concept of student employability. His view of employability is that students acquire the ability to acquire knowledge and develop comprehensive qualities through their schooling, which is a skill not only able to fulfill the ideal of employment, realize their own value, but also meet the needs of society to a certain extent ${ }^{[5]}$.

Li Junkai believes that college students' employability includes professional competence, interpersonal influence, analytical thinking, professional identity, and personality. The subject is an individual, so the employability should be a collection of individuals in knowledge accumulation, basic skills, and work mentality, and should not be constrained by external environmental factors and other conditions. Although these are all objective and even disturbing factors that affect the outcome of employment, these factors should not be included in the scope of employability ${ }^{[6]}$. Xiao Yan and Wang Yanan believe that the employability of college students is the ability and overall quality of successful employment accumulated by the students themselves, emphasizing that the employability is a common skill, and it is the ability to apply to all posts. They all think that employability is a complex system of capabilities ${ }^{[7]}$.

Through the review of domestic and foreign research literature, we find that both Western scholars and domestic scholars have not yet obtained a unified view on the employability. It is not difficult to understand this phenomenon. The reason is that different scholars have different comprehension of capabilities and different definitions of employment. Therefore, the concept of employability cannot be unified. However, for the employment guidance practice of higher vocational education in our country, with the continuous advancement of the popularization process after higher education, employment orientation as a core institution in higher vocational colleges becomes more and more clear. Domestic academic circles have also conducted some exploratory studies on the employment ability of higher vocational students. The definition of unified employability of higher vocational students is of great significance to the employment guidance practice in higher vocational education.

\section{Employability Structure}

\subsection{Overseas Employability Structure}

The Secretary's Commission on Achieving Necessary Skills conducted a comprehensive investigation and in-depth study of the current state of education in the United States in the last 20 years and the demand for talent in the 21 st century in the United States. In its investigation report: The 21st Century American Requirements for Schools, it was pointed out that employers' expectation of employment is not only with solid professional knowledge and professional skills, but also with strong practical ability and practical skills. Only in this way can the needs of work be met. The survey report summarized the "five capabilities" and "three basics." The "five capabilities" are the ability to use and govern all kinds of resources reasonably, the ability to handle interpersonal relationships, the ability to obtain information and use information, the ability to analyze, and the ability to use multiple technologies. The "three basics" are basic qualities (listening, speaking, reading, writing, counting), logical thinking, and moral qualities.

Bridgstock Ruth pointed out in his article that the composition of college students' employability consists of five components: specific professional skills, career planning skills, general skills, personality and personal characteristics, and self-development management capabilities ${ }^{[8]}$.

\subsection{Domestic Employability Structure}

The concept of employability was first introduced by scholar Zheng Xiaoming in China. He divided the employability of college students into individual intellectual and non-intellectual factors, namely, IQ and EQ, or intellectual capital and capability capital. The intelligence factor is the 
"hardware" of the individual's survival and development. The non-intelligence factor is the "software" of the individual's survival and development. The two are complementary and inseparable. The employability of university students can be divided into learning ability, logical ability, hands-on practical ability, candidate ability, environmental adaptability, etc.; in terms of components, a qualified individual who meets the requirements of the applicant should have good intellectual capital and capability capital, which is commonly known as IQ and EQ ${ }^{[5]}$.

Li Junkai based on a questionnaire survey of 2,570 graduates in different regions and universities of different types across the country, analyzed the exploratory factors and confirmatory factors and found that the structural model of university students' employability includes five factors: professional competence, interpersonal influence, analysis and thinking, professional identity, and personality. Among them, personality, analysis and thinking, professional identity are the intrinsic key factors, and professional competence and interpersonal influence are external factors ${ }^{[9]}$. This study not only reasonably sums up and explores the factor composition of employability, but also gives a detailed and profound description of the structural model of the factor and finds out the mutual influence of each factor. This is of positive significance for understanding the complex framework of employability.

Xiao Yan and Wang Yanan, on the basis of defining the definition of employability, compiled a structural scale for the employability of college students based on relevant literature and open questionnaire survey data. The employability structure is divided into three dimensions: human capital, social capital, and psychological capital. Human capital includes learning ability, practical ability and job search ability. Social capital includes the accumulation of social relations and the help of social relations for employment. Psychological capital includes psychological qualities and personal qualities ${ }^{[7]}$. Through project analysis, exploratory factor analysis, reliability and validity analysis, the dimensionality structure of college students' employability was verified. The research conclusions have certain reference value to solve the employment problem of college students.

In summary, the essence of the integrated employment capacity structure is to analyze the influencing factors that affect the employment results of laborers. Many scholars also put forward the two-factor theory, the three-factor theory, the five-factor theory, the seven-factor theory, and even the nine-factor theory of the employability structure from different perspectives and focuses. Although they are different, the essence is the same. The factors of employability structure include knowledge, skills, and individual psychological characteristics. In general, compared with foreign studies, the theoretical foundation for the study of domestic employment capacity structure is weak, the capacity structure is not mature enough, the research method is simple, and there is a lack of innovation.

\section{Definition of employability of vocational students}

This study defines the employability of higher vocational students as follows: higher vocational and technical colleges are aiming for employment while students are in school. Through knowledge learning, professional practice, and social practice, graduates have the comprehensive ability to acquire a variety of knowledge, skills, personality qualities, and attitudes that can make them successful in career, occupation, and professional development. Higher vocational students' employability is a comprehensive ability related to employment. It is a combination of a series of skills and individual characteristics. It is the ability to help vocational students get job smoothly and is capable of obtaining and maintaining work and promotion.

\section{Definition of the Employability Structure of Higher Vocational Students}

For vocational college students, the structural composition of their employability includes a variety of different abilities that students have. Among these capabilities that are included in the employability, there are also significant differences in the importance of different abilities. As far as the actual situation of vocational college education is concerned, student employability mainly 
includes five levels of content, namely, professional ability, individual ability, vocational ability, social ability, and innovation and entrepreneurship.

Professional ability includes professional knowledge and professional skills. Individual ability includes self-awareness, learning ability, and self-adaptability, ability to analyze and solve problems, personality, emotion regulation, and personal image. Vocational ability includes professional planning ability, job search ability, professional ethics and professionalism, ability to collect and process information, ability to seize opportunities, decision-making ability, and marketing ability and so on. Social ability includes interpersonal skills, communication skills, expression skills, teamwork skills, practical skills, and organizational and coordination skills. Innovation and entrepreneurship include awareness, thinking, knowledge and skills.

Through the induction and analysis of the above documents, this paper defines the employment ability structure of higher vocational students as the following five components: professional ability, individual ability, vocational ability, social ability, and innovation and entrepreneurship, which constitute the theoretical model of the employability structure of the vocational college students, as shown in Figure 1. These factors are interlinked, and the improvement of each factor can improve the employability.

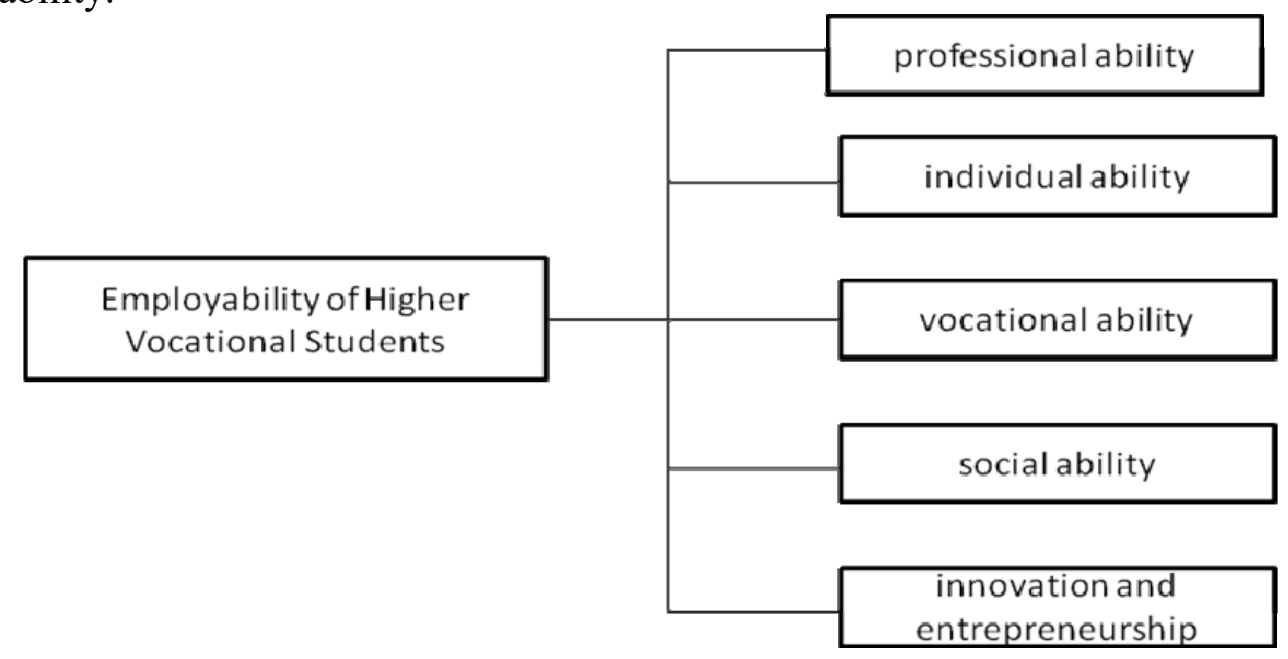

Figure 1 Theoretical Model of Employability of Higher Vocational Students

\section{References}

[1] Freudenberg, Brett \& Cameron, C. WIL and generic skill development: The development of business students' generic skills through work- integrated learning. Asia-Pacific Journal of Cooperative Education, vol.12, pp.79-89. 2011.

[2] Mayer. Putting General Education to Work: The Key Competencies Report[R]. Australian, Education Council and Ministers of Vocational Education. 1992.

[3] Mohd Yusof Husain. Importance of Employability Skills from Employers' Perspective. Procedia Social and Behavioral Sciences, vol.7, pp.430-438. 2010.

[4] Liu Chunlei \& He Xintong. Review on Employability of College Students. Value Engineering, vol. 122, pp.220-221.2015.

[5] Zheng Xiaoming. Employing Ability Theory. Journal of China Institute of Politics, vol. 21, pp. 91-92. 2002.

[6] Li Junkai. Research on the Structure and Influencing Factors of College Students' Employability. Chinese Youth Studies, vol.11, pp.89-92. 2012.

[7] Xiao Yan \& Wang Yanan. An Analysis of the Dimensional Structure of College Students' Employability. Journal of Xi'an Shiyou University (Social Science Edition), vol.1, pp.3-8. 2018. 
[8] Bridgstock Ruth. The graduate attributes we have overlooked: enhancing graduate employability through career management skills. Higher Education Research \& Development. vol.28, pp.31-44. 2009.

[9] Li Junkai. Research on the Structural Model of University Students' Employability. Education Research Monthly, vol.28, pp.64-68. 2013. 